\title{
Scotch Yoke Mechanism for Metal Specimen Polishing \& Microstructure Analysis
}

\author{
Saish N. Rivankar ${ }^{1}$, Prasanna C. Kattimani ${ }^{2}$, Gaurish Walke ${ }^{3}$, Dr. Akshay Nigalye ${ }^{4}$ \\ Department of Mechanical Engineering ${ }^{1,2,3}$, Agnel Institute of Technology \& Design, Goa, 403-507, India ${ }^{1,2,3}$ \\ Department of Mechanical Engineering ${ }^{4}$, Goa College of Engineering, Farmagudi, Goa, 403-401, India ${ }^{4}$ \\ Email: saish.rivankar@gmail.com ${ }^{1}$,pk.aitdgoa@gmail.com ${ }^{2}$,gaurishwalke88@gmail.com ${ }^{3}$,avn@gec.ac.in ${ }^{4}$
}

\begin{abstract}
Preparation of metallographic specimen for revealing microstructure of metals or metal alloys is carried out in material science laboratories all over the world. To study microstructure of metal samples, various steps like sectioning, grinding, polishing, etching are performed, and this procedure requires skills and practice to produce specimen whose microstructure can be seen clearly under the optical microscope. In this research a new concept for polishing machine is proposed, which aims to eliminate all the factors that cause poor surface finish during manual polishing. The proposed polishing machine uses modified scotch-yoke mechanism. Machine minimizes skill and efforts required to prepare metallographic specimen.
\end{abstract}

Index Terms-Metallographic Specimen; Polishing; Scotch Yoke Mechanism; Abrasive Surface.

\section{INTRODUCTION}

Microstructure of materials affects mechanical properties and hence application of the materials is related to microstructure. Therefore, microstructure study is important tool in quality inspection of newly developed material, which includes metal and their alloys. Ma-chines such as SEM \& TEM are available which have capability to study microstructure of materials both quantitatively and qualitatively. But these machines are very costly and needs good utilization factor for better productivity. These machines are not much suitable for educational institutes. Hence, to study microstructure analysis, institutes make use of optical microscope, which is low cost alternative for SEM and TEM. Under optical microscope qualitative analysis and comparative analysis of microstructure can be performed. To view microstructure of any material under optical microscope requires preparation of the metallographic specimen. Microstructure analysis involves specimen identification, sectioning, mounting, grinding, polishing, etching, microscopic analysis and hardness testing [1-2].

Machines for performing grinding and polishing are available with different methods of operation. They involve human interference which creeps in defect on polished surface, making it unfit for viewing microstructure under optical microscope. This requires re-polishing of specimen which leads to increase in cycle time and cost of machining [3].

This research focuses on developing a machine which polishes specimen for microstructure analysis. Preparing a specimen requires rough polishing and fine polishing. Rough polishing makes use of Silicon
Carbide (SiC) Waterproof Emery Paper of lower grit size. Fine polishing requires rubbing rough polished specimen on velvet cloth with alumina powder to give mirror finish. Both operations are performed on developed machine which works on scotch-yoke mechanism, with minimum human interference.

\section{LITERATURE REVIEW}

During the period 1513 to 1517 , Leonardo da Vinci visualized a machine which could be used for grinding and polishing of telescope mirrors. In the concept shown in Fig. 1, circumferential area of polishing wheel is rubbed against the mirror to be ground. Mirror is placed on wheel which is rotated using gear train simultaneously during polishing [4].



Fig. 1. 1st Polishing machine by Leonardo da Vinci

Another machine as shown in Fig. 2, visualized by Leonardo da Vinci, consists of crank-crank mechanism. Main disc carrying mirror rotates, whereas the polishing disc carrying the abrasive layer also rotates over the mirror causing abrading action. Rotation of link connected to cranks causes rotation of main disc about its axis. The other crank is connected to polishing disc through eccentric arm, thus causing revolving motion [4]. 


\section{Available online at www.ijrat.org}

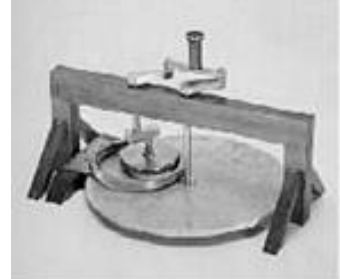

Fig. 2. 2nd Polishing machine by Leonardo da Vinci

A polishing machine used by Romano Zen, shown in Fig. 3, is modified version of polishing machine designed by Henry Draper. Abrasion occurs as specimen holder traces arc on rotating abrasive disc [4].

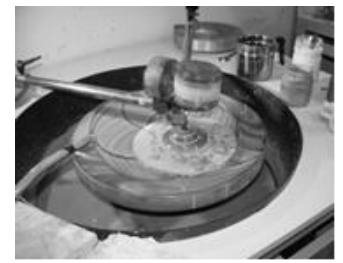

Fig. 3. A polishing machine used by Romano Zen

In the machine shown in Fig. 4, designed by Henry Draper, vertical shaft is connected to the abrasive disc from top end. Rotation of shaft causes rotation of abrasive disc. Pair of pully $\&$ bevel gear train was used to carry out straight line sliding action of specimen holder on top of abrasive disc. Holder could be rotated manually about its axis using hand operated lever [5].



Fig. 4. Polishing machine by Henry Draper

Huygens's designed a polishing machine, shown in Fig. 5, which was operated by hand. The lens blank was sandwiched between the square table and the square rod made of abrasive material. Polishing action was achieved by to and fro motion of bow [6].



Fig. 5. Polishing machine by Huygens's

John P Buckley in 1931 invented a polishing and grinding machine as shown in Fig. 6. The mechanism combines rotary and linear movement. Grinding and polishing of multiple specimen is done along with individual rotation of specimen against abrasive surface causing abrading action. The specimen carriers could be automatically and periodically shifted laterally on the abrading disc [7].



Fig. 6. Polishing machine by John P Buckley

Kurt H. Roth developed an abrading apparatus as shown in Fig. 7, for polishing specimens which has a non-rotating polishing disc. The specimen holder makes local orbital polishing motion over the abrasive surface. The loading of the specimen may be continuously changed during operation of the machine [8].

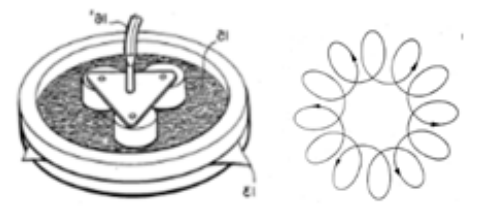

Fig. 7. Polishing machine by Kurt H. Roth

Noburu Shimizu \& Norio Kimura in 1999 developed a polishing machine as shown in Fig. 8, in which the workpiece is pressed against an abrasive surface with pressure. The processing surface makes circulatory translational motion along a predetermined path [9].



Fig. 8. Polishing machine by Noburu Shimizu \& Norio Kimura

Machine by Sr. Wesley H Banta has rotating abrasive disc against which material to be polished is pressed with required pressure. It is used for flat-grinding and polishing gem stones \& petrified wood [10]. 


\section{Available online at www.ijrat.org}



Fig. 9. Polishing machine by Wesley H. Banta

Machine by Davilla Sturtevant Thompson provides opticians an improved \& accurate method of grinding lenses. The machine as shown in Fig. 10, has simple and durable in construction, very effective, noiseless, and automatic in operation. It requires little attention while in action [11].
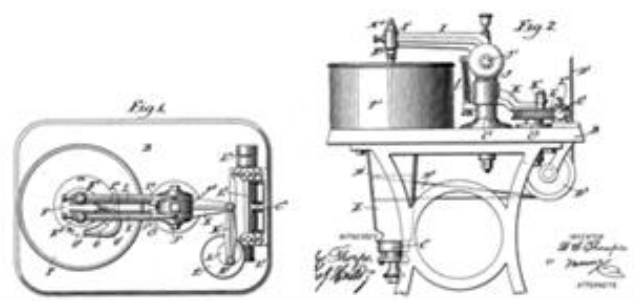

Fig. 10. Grinding machine by Davilla Thompson

The polishing machine as shown in Fig. 11, improves flatness of work on both sides of specimen by incorporating thin plate work piece carrier. Specimen carrier has multiple holes to accommodate multiple work piece. An upper polishing plate polishes an upper face of the work piece. A lower polishing plate pinches the work piece with the upper polishing plate and polishes a lower face of the work piece. A driving mechanism moves the carrier along a circular orbit in a plane without revolving [12].

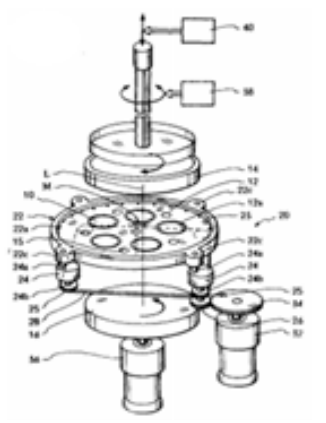

Fig. 11. Polishing machine by Yasuhide Denda

Classification of commercially available polishing machines used for preparing the metallographic specimen are as follows. [13]

(1) Belt polisher
(2) Single disc polishing machine

(3) Double disc polishing machine

\section{POLISHING PROCESS \& PROBLEMS FACED}

Polishing of metal specimen involves abrasion between $\mathrm{SiC}$ grains on polish paper and top surface of the specimen. $\mathrm{SiC}$ grains on polish paper acts as multipoint cutting tool and removes material from surface. Before the development of polishing machines, the specimen was prepared by rubbing the its surface on $\mathrm{SiC}$ papers of gradually increasing grit size to get rough polish as shown in Fig. 12.



Fig. 12. Rough Polishing

After rough polishing, fine polishing was performed by holding the specimen over a rotating disc having velvet cloth on its surface. Fine polishing is aided using alumina powder along with distilled water. Separate machine is used for fine polishing.

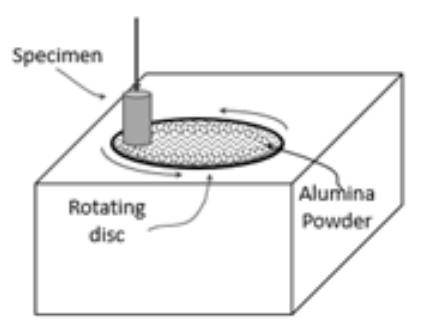

Fig. 13. Fine Polishing

\subsection{Problems faced during polishing}

(1) Uneven material removal during rough polishing.

(2) Rotation of specimen by $90^{\circ}$ w.r.t. previous orientation may not be possible without errors.

(3) Hand fatigue.

(4) Human involvement during polishing steps is major source of errors as surface to be polished cannot be held flat on the polishing disc.

(5) Rough polishing and Fine polishing operations require separate set of procedure and equipments. 


\section{Available online at www.ijrat.org}

\section{CONCEPT DESIGN}

Mechanisms for specimen preparation were studied with consideration for combined translational and rotary motion as shown in Fig. 15. After extensive analysis and brainstorming sessions scotch-yoke mechanism was considered as best and selected for further development. Virtual model as shown in Fig. 14, using SOLIDWORK was created and kinematic motion analysis was carried out. After simulation of created model, it was concluded that machine performance during operational cycle is suitable for metallographic specimen preparation.

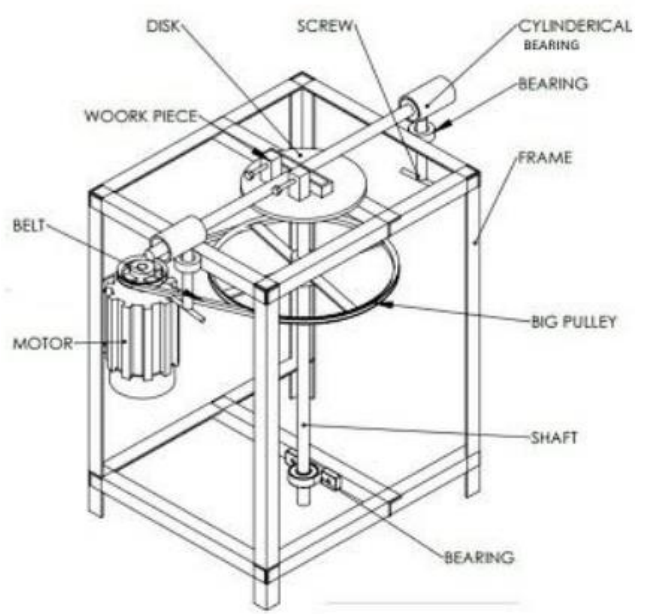

Fig. 14. Isometric view of polishing machine

Machine designed using scotch-yoke has minimum moving components. It neither has chain nor gear drives. The mechanism is powered by 3 Phase induction motor. Speed regulator is provided for speed adjustment as per requirement of polishing speed for the abrasive disc. Abrasive disc of grit size like C60, C80, C120, C220, C320, C400, C800, C1200 are used for rough polishing. Finally, disc with velvet cloth can be used with alumina powder and water to get mirror like finish.

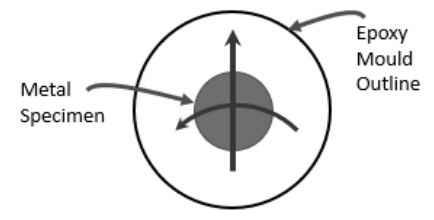

Fig. 15. Picture showing combination of translation and rotation motion while rubbing against abrading surface.

\section{Working Prototype}

Dimensions of the machine structure and its moving components were determined by stress analysis at critical sections. Motor of 0.75 HP was selected considering dynamic and frictional force. Pin connecting disc and the mechanism was designed by considering bending and direct stresses. Mild steel was selected for all structural parts. While designing machine components, factor of safety of 2.5 was considered.

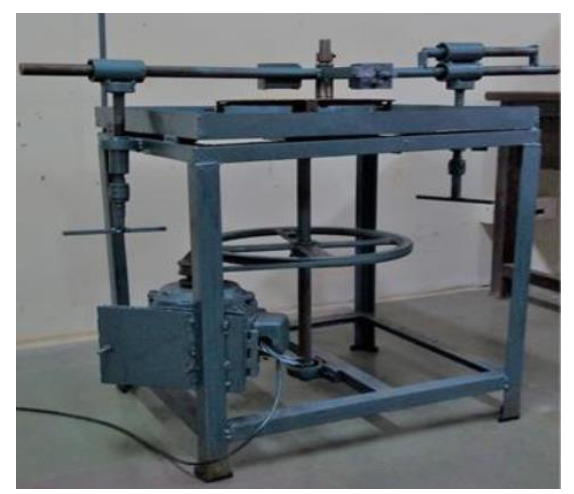

Fig. 16. Working prototype of the polishing machine

\section{Testing}

White cast iron was selected for testing the machine for generation of polished surface. Specimen edges were protected by mounting it in an epoxy resin using rectangular mould as shown in Fig. 17. After specimen preparation, 4\% alcoholic nitric acid (Nital) was applied on fine polished surface to optically enhance grain boundaries. Fig. 17 show results of polishing using $\mathrm{SiC}$ paper of increasing grit size using the machine.

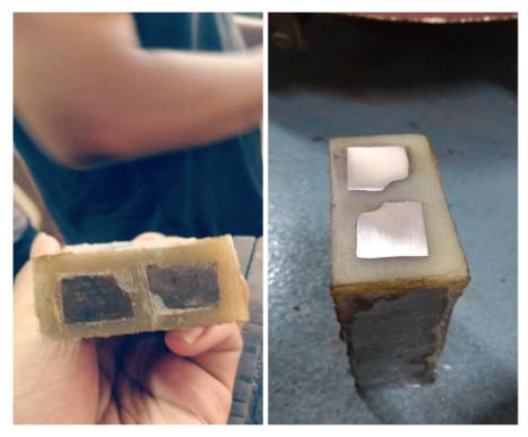

Fig. 17. Before and After Polishing

\section{Conclusion}

White Cast iron specimen was polished using designed machine. Nital was used to optically enhance the microstructure. Microstructure was seen under the micro scope at $100 \mu \mathrm{m}$. Ferrite, Graphite and pearlite phases were identified. The photo of microstructure was clicked by aligning axis of camera with axis of eye piece. It was seen that ferrite phase was surrounding graphite nodules. Qualitatively small amount of perlite was seen. The obtained microstructure was compared with actual microstructure of Cast Iron at $200 \mu \mathrm{m}$. The result 


\section{Available online at www.ijrat.org}

obtained were satisfactory for the demonstration of the working of machine, as shown in Fig. 18. Human interference during polishing process was minimized. Scotch yoke mechanism was successful to combine translation and rotary motion. The total cost of fabrication of machine was INR 16500/-.



Fig. 18. Actual (Left) \& From Fabricated Machine (Right) Microstructure of cast iron under Optical microscope

\section{FUTURE SCOPE}

It was seen that machine vibrations were slightly on higher side during polishing process which may have affected final surface finish of specimen. Further improvements can be made to reduce these vibrations. Mechanism to change the polishing disc automatically can be incorporated to reduce cycle time of process. In-built spirit level can be used to get perfect horizonal surface.

\section{Acknowledgments}

We would like to thank Department of Mechanical Engineering, Fr. Agnel Institute of Technology \& Design, Assagao, Bardez, Goa, 403-401, India for their constant support by providing workshop facility required for fabricating the working prototype of the polishing machine.

\section{REFERENCES}

[1] George, F. (1992): Handbook on Metallography and Microstructures, American Society for Metal (ASM), Materials Park, Ohio, USA, Vol. 9.

[2] McCall, L. (1974): Metallographic Specimen Preparation: Optical and Electron Microscopy, Springer US, Plenum Press, New York.

[3] Joseph, B. (1998): Capstone Design Course: Technical design report, MIM 1501-1502, Project no: W98/S98-4, Dept. of Mechanical, Industrial and Manufacturing Engineering, College of Engineering, NU, Boston.

[4] Erinle, T.J.; Awopetu, O.O.; Ukoba, O.K. (2011): Development of Metallographic Specimen Polishing Machine, The Pacific Journal of Science and Technology, 12 (2), pp. 69-81.

[5] Dorrit H. (1991): The evolution of the Henry Draper memorial, Vistas in Astronomy, 34 (1), pp. 107-162.

[6] Louwman P. (2004): Christiaan Huygens and his telescopes, Proceedings of the International Conference "Titan - from discovery to encounter", ISBN 92-9092-997-9, pp. 103-114.

[7] Epstein, S.; Buckley, P.; (1929), Metallographic Polishing. I. Automatic Metallographic Polishing Machine, Bureau of Standards Journal of Research, 3 (1), pp. 783-794.

[8] Kurt, H.; (1975): U.S. Pat., 3,906,678 A.

[9] Noburu, S.; Norio, K.; (2003): European Pat., EP 0807492 A2.

[10] Sr. Wesley, H.; (1962): U.S. Pat., 3, 061, 981 A.

[11] Davilla S. T.: U.S. Pat., 621, 181 A.

[12] Yasuhide. D.; Atsushi, K.; Satoki, K.; Fuminari, K.; Yoshio, N.; Haruo S. (2003): European Pat., EP 0940221 A3.

[13] Bartels, H.; Samuels, L. E.; (1972): Metallographic Polishing by Mechanical Methods, Transactions of the American Microscopical Society, 91(2), pp. 248. 